\title{
JOGOS ESPORTIVOS TRADICIONAIS E SAÚDE SOCIAL
}

Pere Lavega*

\begin{abstract}
RESUMO
A revisão do conceito de jogo esportivo tradicional, bem como o conceito de saúde e de qualidade de vida requer a adoção de uma visão sistêmica quando se trata de interligá-los. O conceito de saúde refere-se a um fenômeno poliédrico complexo, caracterizado por aspectos humanos tanto subjetivos quanto objetivos, mais do que como ausência de doença, pois corresponde ao bemestar físico, mental e social da pessoa. Essa saúde também está relacionada com a posição individual que cada um alcança na vida, dependendo do contexto cultural, seus valores e expectativas. Ao participar de um jogo esportivo tradicional (JET) cada jogador ativa condutas motrizes. Uma conduta motriz é multidimensional e é caracterizada por estar associada a uma significação externa (aquilo que observamos) e uma interna (experiência do corpo; imagem mental; emoção) que ativa, de uma só vez, as biológicas, cognitivas, afetivas e sociais da pessoa. Estas condutas motrizes têm significados referentes ao contexto social e cultural em que a pessoa vive. Partindo dessas considerações, neste estudo, nós realizamos uma análise da contribuição de JET na dimensão social de saúde e qualidade de vida. As relações interpessoais, o diálogo social, a socialização a partir de distintas interações motrizes no contexto cultural em que vivemos são algumas das contribuições mais conhecidas de JET nesta dimensão.
\end{abstract}

Palavras-chave: Jogo tradicional. Praxiologia motriz. Qualidade de Vida. Saúde Social.

\section{SAÚDE E QUALIDADE DE VIDA COMO FENÔMENOS POLIÉDRICOS}

O conceito de saúde deve ser tratado como um fenômeno poliédrico que consiste em um conjunto de diferentes fatores. Já em 1948, a Organização Mundial da Saúde (OMS) associava ao conceito de saúde como "um estado de saúde física, mental e de bem-estar social, e não meramente a ausência de doença ou enfermidade" (OMS, 1948 ${ }^{1}$ ). O conceito inicial de saúde foi enriquecido pela incorporação do conceito de qualidade de vida. A OMS cria, em 1991, um grupo multicultural de especialistas que se articulam sobre a definição de qualidade de vida como "a percepção do indivíduo sobre sua posição na vida, no contexto cultural e no sistema de valores nos quais ele vive e em relação aos seus objetivos, expectativas, padrões e preocupações" (1994).

O conceito de qualidade de vida é mais amplo do que o de saúde, uma vez que inclui a possibilidade de realização pessoal em todas as dimensões vitais, sendo a saúde a condição mais básica dentre essas dimensões, tanto quanto a ausência de saúde nega ou diminui a qualidade de vida. O "World Health Organi-

\footnotetext{
${ }^{1}$ Definição que apareceu no preâmbulo da Constituição da Organização Mundial de Saúde, como tendo sido adotado na Conferência Internacional da Saúde, em Nova York, 19-22 junho de 1946, assinado em 22 de julho 1946 por representantes de 61 estados, e entrou em vigor em 7 abril de 1948.
}

* Professor do Departamento "Fundamentos de la Motricidad y su Enseñanza", del Instituto Nacional de Educación Física de Cataluña (INEFC), Universidad de Lleida, España. 
zation Quality Of Life Project (WHOQOL) 2" é projeto, iniciado em 1991, com o objetivo de desenvolver um instrumento de avaliação culturalmente comparável a um índice internacional de qualidade de vida. Ele avalia a percepção do indivíduo no contexto de sua cultura e sistema de valores e seus objetivos pessoais, padrões e preocupações, incluindo 26 itens que medem aspectos nos principais domínios: saúde física; saúde psicológica; relações sociais; e meio ambiente. Essa abordagem requer a superação do modelo biomédico (biológico) do conceito de saúde e de qualidade de vida para chegar a um modelo integral e sistemático, de modo a corresponder de maneira uniforme às dimensões biológicas, psicológicas, sociais e culturais do indivíduo. Considerando as limitações de número de páginas neste artigo vamos apenas explorar os benefícios ou as contribuições dos jogos tradicionais para a dimensão social e cultural da saúde.

\section{CONCEITO DE JOGO ESPORTIVO TRADICIONAL}

Jogo tradicional, bem como outros conceitos como jogo ou esporte, tem sido estudado e interpretado a partir de diferentes pontos de vista, disciplinas ou áreas do conhecimento. Ainda assim, o conceito não é suficiente para ser usado no campo científico. Neste texto, a base teórica de referência está fundamentada na ciência da ação motriz ou praxiologia motriz.

Por essa razão, antes de justificar a relação entre jogo e saúde ou qualidade de vida é necessário pautar a diferença entre os conceitos de jogo quase esportivo, jogo esportivo, ou jogo institucional esportivo ou esporte, ou quase esporte.

\subsection{Do jogo tradicional ao esporte}

Por jogo esportivo entendemos "uma situação de confronto motriz codificada, chamada de jogo ou de esporte por suas circunstâncias sociais. Cada jogo esportivo é estabelecido por um sistema de regras que determina a sua lógica interna" (Parlebas, 2001, p.276).

Esta definição não faz julgamento prematuro sobre o conteúdo dos jogos esportivos e deixa o campo aberto para todo o tipo de análise. A instituição do critério, portanto, convida à distinção de duas grandes categorias lúdicas, socialmente marcadas: os jogos institucionais esportivos e os jogos tradicionais esportivos.

O jogo esportivo institucional ou o esporte "é um jogo esportivo conduzido por uma instituição reconhecida oficialmente (federação) e consagrada em consequência das instituições esportivas; logo, um jogo esportivo institucional é um esporte". Estes jogos são apresentados pela autoridade de instituições oficialmente reconhecidas (federações internacionais, comitês olímpicos...), pois elas são regidas por rigorosos regulamentos registrados e reconhecidos. O seu desenvol-

\footnotetext{
${ }^{2}$ Projeto da Organização Mundial de Saúde para a Qualidade de Vida [em tradução livre].
} 
vimento está ligado à espetacularização que, por sua vez, está atrelado aos processos socioeconômicos de produção e consumo. A referência ao conceito de instituição requer a intervenção de instituições poderosas que oferecem uma grande quantidade de materiais, e estrutura: comitês diretivos, regulamentos, calendários, árbitros, pessoal administrativo, mecanismos financeiros, sanções, etc. Nesta linha, o institucional tenta estender o reconhecimento mundial a todos os jogos esportivos adotados (Parlebas, 2001, p.281). Cito, como exemplos, o futebol, o basquete, o handebol e o atletismo.

O jogo esportivo tradicional é "um jogo frequentemente desempenhado numa longa tradição cultural, e que não é regulamentado pelas instituições sociais". Muitas vezes, esses jogos estão ligados a uma tradição muito antiga, e seu sistema de regras admite uma série de variações, dependendo da vontade dos jogadores, e não de instituições oficiais; por isso, ocorre de serem ignorados pelos processos socioeconômicos. Enquanto no jogo institucional há uma instituição centralizadora que faz as regras, podemos dizer que, com a intenção de estendêlas a todos, o jogo tradicional permite localmente que a tradição cuide da transmissão de seus códigos e rituais. As regras vão sendo estabelecidas pelos grupos que praticam o jogo, dependendo de costumes e características locais. O mesmo jogo pode resultar em novas formas de jogar, que podem se tornar novos jogos (Parlebas, 2001, p.286). Existe uma quantidade incrível de jogos de bola, jogos com tacos, jogos infantis ou jogos adultos, que são jogados com as regras locais sem calendário rigoroso, e em muitas ocasiões até fazem parte das festividades locais.

No entanto, vale citar uma eterna divisão pejorativa entre trabalho - considerada uma atividade nobre - e jogo - acusado de ser uma distração de crianças -, e lembrar que essa divisão aparece reproduzida entre o jogo institucional, proclamando sua seriedade e nobreza, e o jogo tradicional, sendo chamado de infantil e inferior. No entanto, antes de estabelecer hierarquias a serviço das ideologias duvidosas, será preferível explorar o escopo das práticas lúdico-motrizes, onde o esporte é um subconjunto rico, e o estudo em profundidade de seus diferentes elementos. Aqui, a cultura da biodiversidade parece mais enriquecida do que a alienação dogmática de apenas um modelo. Olhando para estas observações, é necessário iniciar uma reflexão científica - e crítica, portanto - sobre a teoria dos jogos esportivos, como Parlebas (2001) afirma e entende.

Entre o jogo esportivo tradicional e o jogo esportivo institucional encontramos o quase esporte chamado geralmente de esporte tradicional, que corresponde ao "jogo esportivo que goza de um grande reconhecimento institucional em nível local, mas não conseguiu ainda o inquestionável status internacional" (Parlebas, 2001, p.50). Eles são jogos semi-institucionalizados em que a "esportivização" é muito desenvolvida, mas não completa e, portanto, não atingiram ainda o status internacional. Há exemplos de muitos jogos de luta, jogos de boliche, de bola, para os quais a federação tem caráter regional.

Também indicam que, no extremo oposto ao esporte, encontram-se os jogos quase esportivos correspondentes a "uma atividade física livre e não formal 
chamada normalmente de esporte ou jogo com carência de regras e de competição" (Parlebas, 2001, p.53). Estas são atividades físicas que, por não estarem sujeitas a regras precisas, são atividades motrizes que começam pela própria iniciativa de seus participantes, que tentam buscar um entretenimento imediato que não é dependente de regulação externa com finalidade competitiva. Exemplos dessas atividades auto-organizadas são o brincar com um pião, com um Bilboquê, um ioiô, um aro.

\section{RELAÇÃO ENTRE O JOGOESPORTIVO TRADICIONAL E SAÚDE OU QUALIDADE DE VIDA}

Desde que o referencial teórico relacionado com saúde ou qualidade de vida é construído a partir de uma abordagem sistêmica, é bem necessário examinar sua relação com o jogo esportivo tradicional a partir de uma visão sistemática. Portanto, a praxiologia motriz ou ciência da ação motriz, criada por Parlebas, é a disciplina científica em que este trabalho é embasado, já que supera modelos obsoletos de análise de esportes e jogos, que curiosamente ainda estão ativos no campo da educação física. O modelo mecanicista, apoiado em disciplinas como a biomecânica ainda é válido; este modelo é inspirado no paradigma cartesiano que tende a reduzir os princípios da fisiologia para as condições físicas, onde as regras da mecânica são consideradas suficientes para explicar como uma pessoa age; a explicação dos jogos esportivos vem sendo feita a partir do modelo biomecânico de compreender a ação motriz de cada jogador como uma simples máquina que ativa uma compensação ordenada das articulações dos ossos e grupos musculares que, assim, funcionam como uma soma de engrenagens. Este modelo não está superado pela abordagem fisiológica que reduz a interpretação da ação motriz de um jogador para a análise do esforço e da energia que o atleta consome. Nem satisfaz tentar interpretar a intervenção de um jogador num jogo de modelo cibernético ao associar sua ação motriz a um computador que processa a informação recebida e dá, muitas vezes, uma resposta em termos reducionistas de estímulo-resposta como se a pessoa fosse um autômato completamente autorregulado em quem as decisões estão todas programadas.

Diante desses modelos reducionistas, Parlebas propõe um ponto de vista sistêmico, conflitante com outras abordagens. Ele afirma que o protagonista desta abordagem é a significação, o simbólico, a metacomunicação, a motricidade, cujos dados mecânicos, energéticos e informacionais permanecem sujeitos à atribuição de um significado pelo sujeito ativo, o que significa que se materializa na decisão motriz (Parlebas, 2001). Um pelotari (jogador de um jogo tradicional de bola da Espanha) que decide devolver a bola para a parede não apenas executa certos movimentos, como tenta antecipar o movimento de se colocar lá para onde a bola vai, provavelmente; assim, acerta a bola com intenções diferentes a cada jogada. Não é apenas sobre gestos, movimentos e técnicas, mas também sobre a ação global de uma pessoa que improvisa uma ação motriz de acordo com as regras do jogo e da dinâmica de cada conduta motriz (localização dos jogadores, 
rapidez de movimentos, posição para onde bater a bola a partir de...). É a personalidade do jogador que está em jogo: são as habilidades cognitivas que permitem que o jogador, para avaliar cada situação que muda constantemente, e que permitem ao jogador pré-operar a jogada; também os recursos afetivos que tomam forma nas reações emotivas, no caminho de assumir riscos e também na disponibilidade de conflito relacional, como, por exemplo, para a comunicação motriz que pode ser estabelecida através do confronto. Portanto, as diferentes dimensões da personalidade: biológica, afetiva, cognitiva e relacional são ativadas por sua vez na conduta motriz dos jogadores.

O conceito sistêmico de conduta motriz se refere em considerar a pessoa como um todo agindo, dando sentido a cada uma das respostas da natureza dessa motricidade. Parlebas (2001) define o conceito de conduta motriz como "organização significativa da participação motriz. A conduta motriz é a participação da motricidade como portadora de significado. É a organização significativa de ações e reações de uma pessoa que age, cuja relevância de expressão é de natureza motriz. Uma conduta motriz só pode ser observada indiretamente, já que é manifestada por uma participação motriz em que os dados de observação têm sentido justo, e é a experiência, consciente ou inconscientemente, da pessoa pela própria atuação. Por exemplo, quando filmamos um jogador de vôlei, registramos suas imobilidades, suas mudanças de localização no espaço, pulando e batendo na bola, em resumo, a sua participação motriz; falamos sobre a conduta motriz quando tentamos alcançar, com todos essas manifestações objetivas, o significado das experiências que estão diretamente associadas (percepção, intenção, imagem mental, o projeto, motivação, desejo, frustração...). [...]"

De fato, a conduta motriz não pode ser reduzida a uma sequência de e-
ventos observáveis, nem é uma consciência pura separada da realidade.
Corresponde à totalidade da pessoa que atua, com uma síntese unitária
da ação significativa, ou, se preferem, o significado agido. Esta dupla
perspectiva combina o ponto de vista da observação externa (comporta-
mento observável) e o interno significativo (a experiência do corpo: a
percepção, a imagem mental, expectativa, emoção...) e permite que o
conceito de conduta motriz vá desempenhar um papel crucial na educa-
ção física (PARLEBAS, 2001, p.85).

Embora, nos últimos anos a educação física e os licenciados em atividade física, assim como a ciência do esporte, tenham melhorado o seu estatuto social, o professor de educação física ainda está baseado em conhecimentos dispersos e desconexos, sem qualquer organização teórica coerente ou de aplicação coerente, já que trabalha com conceitos nem sempre atualizados em relação aos paradigmas existentes. A modernização tecnológica e o progresso social não têm acompanhado o renascimento do conhecimento científico; portanto, os procedimentos ainda são arcaicos (Lagardera \& Lavega, 2005). É essencial que a educação física definitivamente abrace os princípios da física quântica, da biologia embrionária, das ciências humanas e sistêmicas para ser capaz de entender o ser humano como um sistema inteligente que reage como uma totalidade-total, mesmo que apenas uma de suas partes esteja sendo estimulada, e que, sobretudo, 
possa cumprir, de forma decisiva e pragmática, essas fundações de vida já universalmente aceitas.

Tabela 1. Currículo de ideias e fatores associados aos conceitos de saúde, de qualidade de vida e de conduta motriz

\begin{tabular}{|c|c|}
\hline $\begin{array}{l}\text { Conceito de saúde ou quali- } \\
\text { dade de vida }\end{array}$ & Conceito de Conduta Motriz \\
\hline Fenômeno poliédrico & Fenômeno Multidimensional \\
\hline $\begin{array}{l}\text { Aspectos subjetivos (percep- } \\
\text { ção individual) \& Aspectos } \\
\text { objetivos }\end{array}$ & $\begin{array}{l}\text { Significado externo + significado } \\
\text { interno } \\
\text { (experiência corporal, imagem } \\
\text { mental, emoções) }\end{array}$ \\
\hline $\begin{array}{l}\text { Mais do que ausência de do- } \\
\text { enças é, sobretudo: } \\
\text { - o bem-estar físico } \\
\text { - o bem-estar psicológico } \\
\text { - o bem-estar social, } \\
\text { e a posição na vida de acordo } \\
\text { com seu contexto cultural, os } \\
\text { valores, as expectativas... }\end{array}$ & $\begin{array}{l}\text { Ativa de forma homogênea as } \\
\text { diferentes dimensões: } \\
\text { - biológica; } \\
\text { - cognitiva; afetiva; } \\
\text { - social, } \\
\text { no contexto social e cultural em } \\
\text { que vive a pessoa }\end{array}$ \\
\hline
\end{tabular}

Fonte: Com base nos dados de Lavega, 2012.

\section{BENEFÍ́CIOS DOS JOGOS ESPORTIVOS TRADICIONAIS PARA A DI- MENSÃO SOCIAL DA SAÚDE}

Numa pesquisa realizada por Moscoso \& Moyano (2009), a população espanhola investigada relatou estar muito satisfeita com a vida, com altos níveis de bemestar e de qualidade de vida. Dentre os aspectos específicos para a qualidade de vida destacaram a importância das relações interpessoais, o que também foi confirmado em outros países do Mediterrâneo por outros estudiosos que esses mesmos autores citam, como Antonucci et al. (1996), Fernandez-Ballesteros, Zamarron, Rudinger et al. (2005), Fernandez-Ballesteros, Zamarron e Macia (1996).

Para as pessoas mais velhas, o exercício físico é uma maneira extraordinária para restaurar os laços sociais, porque essas atividades estão sendo realizadas fora de casa; especialmente esse aspecto é muito importante para as mulheres idosas, para combater riscos como a depressão, a solidão e o desânimo.

Em vários estudos sobre jogos tradicionais esportivos em diferentes regiões da Europa (Etxebeste, 2001; Lavega, 2006 e Lopez Sosoaga, 2006), e em outras regiões do Mediterrâneo e de África (Bouzid, 2000; Elloumi, 2000) usando uma abordagem etnomotriz, a presença de uma ampla gama de jogos sóciomotores, que requerem a interação motriz com outras pessoas, foi confirmada.

Estudos realizados sobre jogos tradicionais referentes à primeira metade do Séc. XX confirmam a predominância de sócio-motricidade em várias regiões do Mediterrâneo, como a Catalunha (74,7\%), País Basco (76,7\%), Valência (85\%) e Tunísia (84\%), como se constata no gráfico da Figura 1, a seguir. 


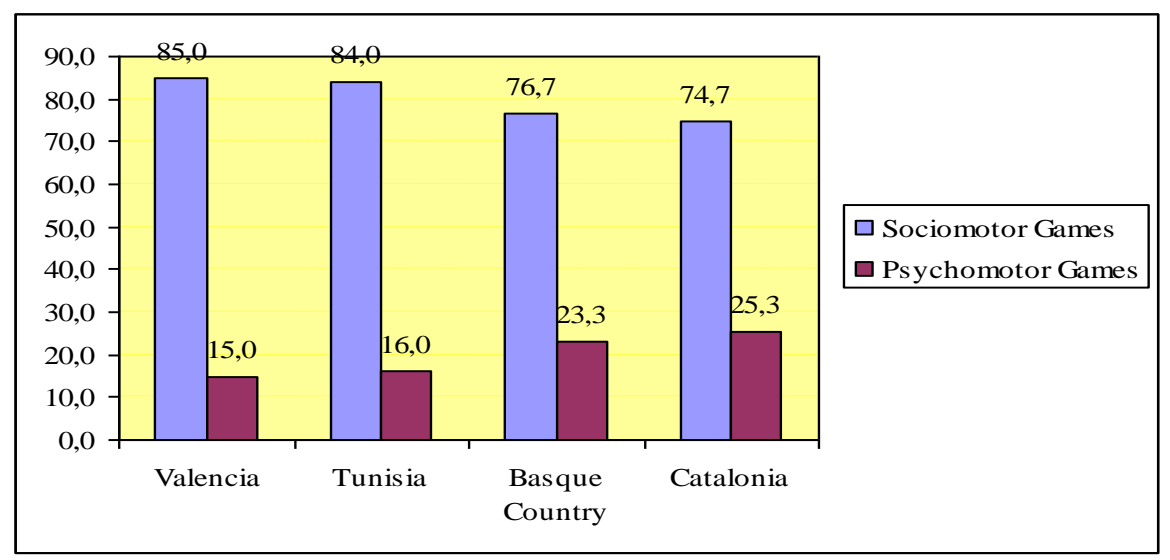

Fig.1 - Gráfico de distribuição (percentual) de jogos tradicionais sócio-motores e jogos tradicionais psicomotores em várias regiões mediterrânicas de Espanha e Tunísia. Jogos sócio-motores exigem interação motriz com outros jogadores, mas em jogos psicomotores os jogadores estão sozinhos,

interagir com outros participantes; (Valência: 15 e 85\%; Tunísia, 16 e 84\%; País Basco, 23,3 e 76,7\%; Catalunha, 25,3 e 74,7\%, de jogos psicomotores e jogos sócio-motores, respectivamente).

Entre as opções do jogo a pessoa pode cooperar com os parceiros, oporse aos rivais, participar com os outros para resolver um desafio comum, propor estratégias de equipe, participar de redes de comunicações motrizes originais, tais como intervir nos jogos em que é possível mudar de parceiros ou adversários ao jogar ou fazer jogos paradoxais em que outros participantes podem, ao mesmo tempo, serem companheiros e adversários. Tradicionalmente, os jogos esportivos tradicionais devem ser entendidos como uma sociedade em miniatura ou como um laboratório de relações motrizes. Estas atividades desenvolvem a socialização entre os jogadores com base no descobrir, reconhecer e compartilhar experiências com os outros. Por esta razão, jogos esportivos tradicionais tornam-se um cenário extraordinário para possibilitar a socialização de um estilo de vida saudável baseada em relações interpessoais.

Em uma pesquisa feita em várias regiões europeias (Lavega, 2006) dentro do programa oficial da cultura europeia (2000) sobre jogos esportivos tradicionais praticados por adultos, os resultados confirmaram a alta dimensão integradora desses jogos. Se considerarmos o sexo dos protagonistas, podemos observar a presença de jogos mistos (39\%), especialmente em um contexto de férias, e também jogos masculinos (38\%) e jogos femininos (5\%). Ao mesmo tempo, há jogos em que homens e mulheres jogam em separado (18\%), principalmente em campeonatos de jogos esportivos federados. Ao mesmo tempo, podemos ver que há também jogos jogados por pessoas de diferentes idades, especialmente quando 0 contexto não é um torneio ou uma competição. Estes dados não poderiam ser encontrados no âmbito do esporte profissional, o que confirma a grande contribuição dos esportes tradicionais para a dimensão social da qualidade de vida e da saúde, como mostra o gráfico da Figura 2, a seguir. 


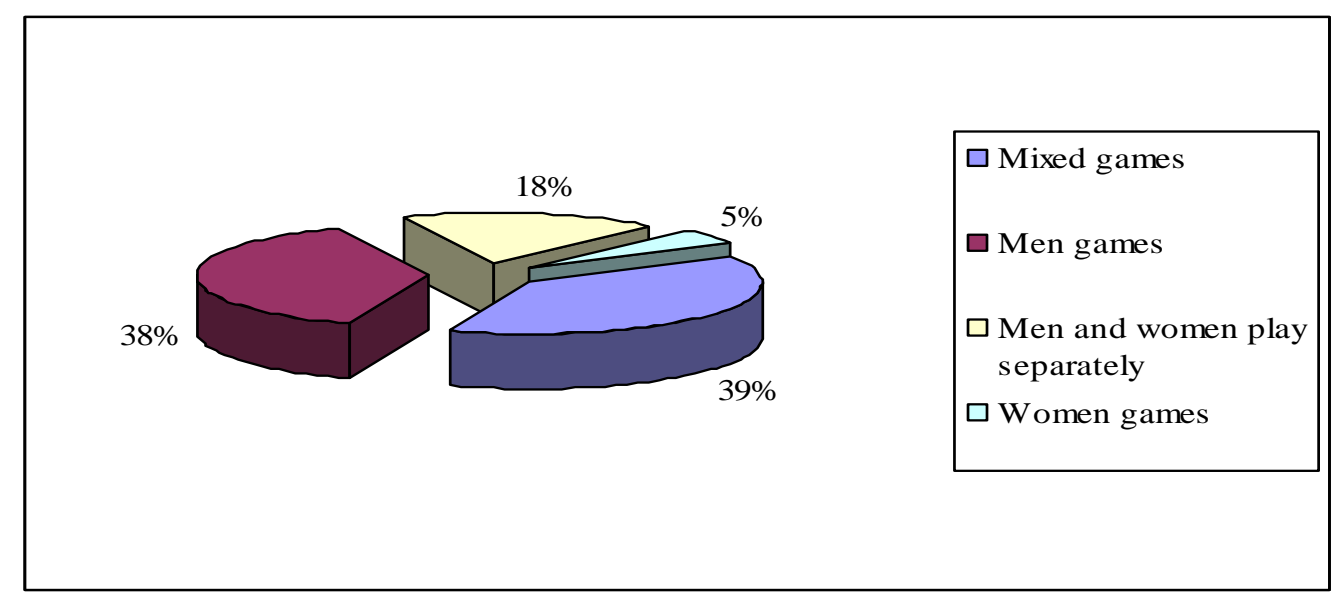

Fig. 2. Gráfico dos resultados da composição dos grupos de adultos por gênero em jogos tradicionais presentes em diferentes regiões europeias: (39\% de jogos mistos; $38 \%$ de jogos masculinos; $18 \%$ de jogos masculinos ou femininos separados; e $5 \%$ de jogos femininos).

As festas regionais ou celebrações populares são dos eventos mais importantes desses contextos, nos quais os jogos esportivos tradicionais alcançam seu máximo significado. Ao longo de cada contexto festivo o jogo melhora a interrelação entre os diversos grupos sociais, ajudando a ativar a harmonia da convivência e a relação com os outros. Além disso, em uma sociedade onde o multiculturalismo está se tornando cada vez mais presente, é necessário reconhecer a dimensão social do jogo, o que implica promover o direito de ser diferente, de compartilhar os "nossos" e os "seus" jogos para promover uma cultura de paz, baseada na democracia, permitindo a integração de todos os participantes no contexto coletivo ao qual pertencem. Atualmente, existem muitos lugares ainda na Europa e em outros continentes, onde os jogos tradicionais são um ingrediente essencial das festividades locais. De fato, os resultados obtidos na organização de jogos tradicionais em várias regiões europeias mostram a extraordinária importância dos grupos locais, como associações de bairro, organização de comitês para uma feira ou festival, associações culturais ou clubes, organizações de trabalho (p.ex.: fraternidades, cooperativas, associações de agricultores), instituições públicas e comerciais da cidade, que celebram as festividades.

Sem dúvida, todos esses dados confirmam o excelente contributo dos jogos tradicionais na melhoria das várias dimensões da saúde ou da qualidade de vida. A visão sistêmica dos jogos tradicionais, bem como a saúde ou a qualidade de vida pode justificar um papel muito necessário dos jogos tradicionais no Séc. XXI.

\section{REFERÊNCIAS}

Bouzid, E. (2000). Study of adult and children sporting games of two periods of Tunesia history: the Roman period and the Actual period. In Ministère Jeunesse, Enfance et Sports de la République Tunisienne (Eds.), Games, Sports and Societies. Proceedings of Tunisia-French Congress (pp. 35-54). Tunis: CERDOJES (In French/ em Francês). 
Elloumi, A. (2000). Socio-cultural Tunisian traditional games. In Ministère Jeunesse, Enfance et Sports de la République Tunisienne (Eds.), Games, Sports and Societies. Proceedings of Tunisia-French Congress.Tunis: CERDOJES (In French/ em Francês).

Etxebeste, J. (2001). The Sporting Games, Elements of traditional socialization of children in the Basque Country. University Paris V-Rene Descartes, Paris. (In French/ em Francês).

Lagardera, P., \& Lavega, P. (2005).The physical education as pedagogy of motor behaviour. Tandem. Revista de Educación Física, 79-101 (In Spanish/ em Espanhol).

Lavega, P. (2004). Traditional games and education. To learn to create bonds. To create bonds to learn. Studies in physical culture \& Tourism. University School of Physical Education in Poznar (Poland), Vol. XI 1: 9-32.

Lavega, P. (Ed.). (2006). Traditional games and society in Europe. Barcelona: European Traditional Games and Sports Association. (In Spanish/em Espanhol)

López de Sosoaga, A. (2006 ). Children games and adult games, two different realities? In R. Martínez de Santos \& J. Etxebeste (Eds.), Investigations in motor praxeology (pp.11-20). Vitoria: AVAFIEP and Universidad del País Vasco. (In Spanish/em Espanhol)

Moscoso, D., \& Moyano, E. (Eds.). (2009). Sport, health and quality of life. Barcelona: Fundación "La Caixa" (In Spanish/ em Espanhol).

Parlebas, P. (1999). Games, sports and society. Barcelona: Paidotribo. (In Spani$\mathrm{sh} /$ em Espanhol)

World Health Organization (1993). WHOQoL Study Protocol. WHO (MNH7PSF/93.9). Retreived 10 June $2010<$ http://www.who.int/substance_abuse/research_tools/en/english_whoqol.pdf >

\section{TRADITIONAL SPORTS GAMES AND SOCIAL HEALTH}

\section{ABSTRACT}

The review of the concept of traditional sporting game as well as the concept of health or quality of life requires adopting a systemic vision when it comes to linking them. The concept of health refers to a complex polyhedral phenomenon, characterized by the subjective and objective aspects of the person, than with the sickness absence, correspond with the physical, mental and social well-being of the person. It is also related with the individual position each one has in life, depending on the cultural context, values and expectations. When participating in a traditional sporting game (TSG) 
each player activates motor conducts. A motor conduct is multidimensional and it's characterized for being associated to an external signification (what we observe) and an internal one (body experience, mental image, emotion...) that activates, at once, the biological, cognitive, affective and social dimensions of the person. These motor conducts are full of meaning in the social and cultural context where the person lives. Proceeding form these considerations, we accomplish in this text a review of the contribution of TSG in the social dimension of health and quality of life. The interpersonal relationships, the social dialog, the socialization starting from different motor interactions in the cultural context in which we live are some of the most well-known contributions of TSG in this dimension.

Keywords: Motor Praxeology. Quality of Life. Social Health. Traditional Game.

\section{JUEGOS DEPORTIVOS TRADICIONALES Y LA SALUD SOCIAL}

\section{RESUMEN}

Una revisión del concepto de juego deportivo tradicional, y el concepto de salud y calidad de vida requiere la adopción de una visión sistémica cuando se trata de vincularlos. El concepto de salud se refiere a un fenómeno poliédrico complejo, caracterizado por los aspectos humanos subjetivos y objetivos, más que la ausencia de enfermedad, corresponde al bienestar físico, mental y social de la persona. La salud también está relacionada con la posición que cada individuo logra en la vida, dependiendo del contexto cultural, de sus valores y expectativas. Al participar en un juego deportivo tradicional (JDT), cada jugador activa conductas motrices. Una conducta motriz es multidimensional y se caracteriza por estar asociada a una significación externa (lo que observamos) y una interna (experiencia del cuerpo, la imagen mental, la emoción) que activa, a la vez, lo biológico, cognitivo, afectivo y social de la persona. Estas conductas motrices tienen significados relacionados con el contexto social y cultural en que vive la persona. Sobre la base de estas consideraciones, en este estudio, se realizó un análisis de la contribución de JDT en la dimensión social de la salud y calidad de vida. Las relaciones interpersonales, el diálogo social, la socialización a partir de las interacciones motrices en el contexto cultural en el que vivimos son algunas de las aportaciones más conocidas de los Juegos Deportivos Tradicionales en esta dimensión.

Palabras clave: juego tradicional. Praxiología motriz. Calidad de Vida. Salud social.

Endereço para correspondência: plavega03@gmail.com

Tradução: Josefina Neves Mello

Revisão Técnica: João Francisco Magno Ribas 